\title{
What patients wish health professionals knew about partnering with them
}

\author{
— Cite as: CMAJ 2021 July 12;193:E1056-8. doi: 10.1503/cmaj.1095951
}

Posted on cmajnews.com on June 22, 2021

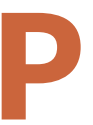

atients have played an increasing role in health care research and decisions over the past decade. However, challenges persist around compensation and meaningful engagement. CMAJ reached out to five patient partners across the country for their perspectives: Louise Bird, a patient family advisor for the Saskatchewan Cancer Agency and other organizations, Ovey Yeung, a Vancouver-based patient partner with the Patient Voices Network, Zal Press, vice-chair of the patient and community advisory committee at the Canadian Agency for Drugs and Technologies in Health (CADTH), Amy Ma, a Montreal-based patient and public advisor for Choosing Wisely Canada, and Francine Buchanan, a patient engagement advisor to multiple research teams in Ontario. Their responses have been edited for clarity and length.
CMAJ: What do you wish researchers and health systems understood about partnering with patients?

Yeung: Every single time patients tell their story, it's traumatizing for them... I have all these articles about my case: research it. Then you can ask me stuff that isn't already out on the web... It makes it less painful.

Press: There's a quote by Don Berwick, the CEO of the Institute for Healthcare Improvement in the States: "If you don't think health care is about power, you haven't been paying attention." The power dynamic in that sacred space of the therapeutic relationship is where it all begins... If we don't understand how the exercise of power in that relationship actually works, then it makes for a very difficult proposition to address change.

Bird: Never assume that because you have three patients who have the same medical condition that their story is going to be the same. Everybody has a unique experience to share.

Ma: I would like to see the research world meet people where they are... it takes a lot of energy to organize around meetings, because it's once a month, or once a quarter, but it's not in your community, it's back where you had your treatment. There's been a lot of talk lately about increasing diversity and inclusion around the table, but maybe we have to rethink the whole idea [of gathering people around one table] and meet them on their terms, in their territory.

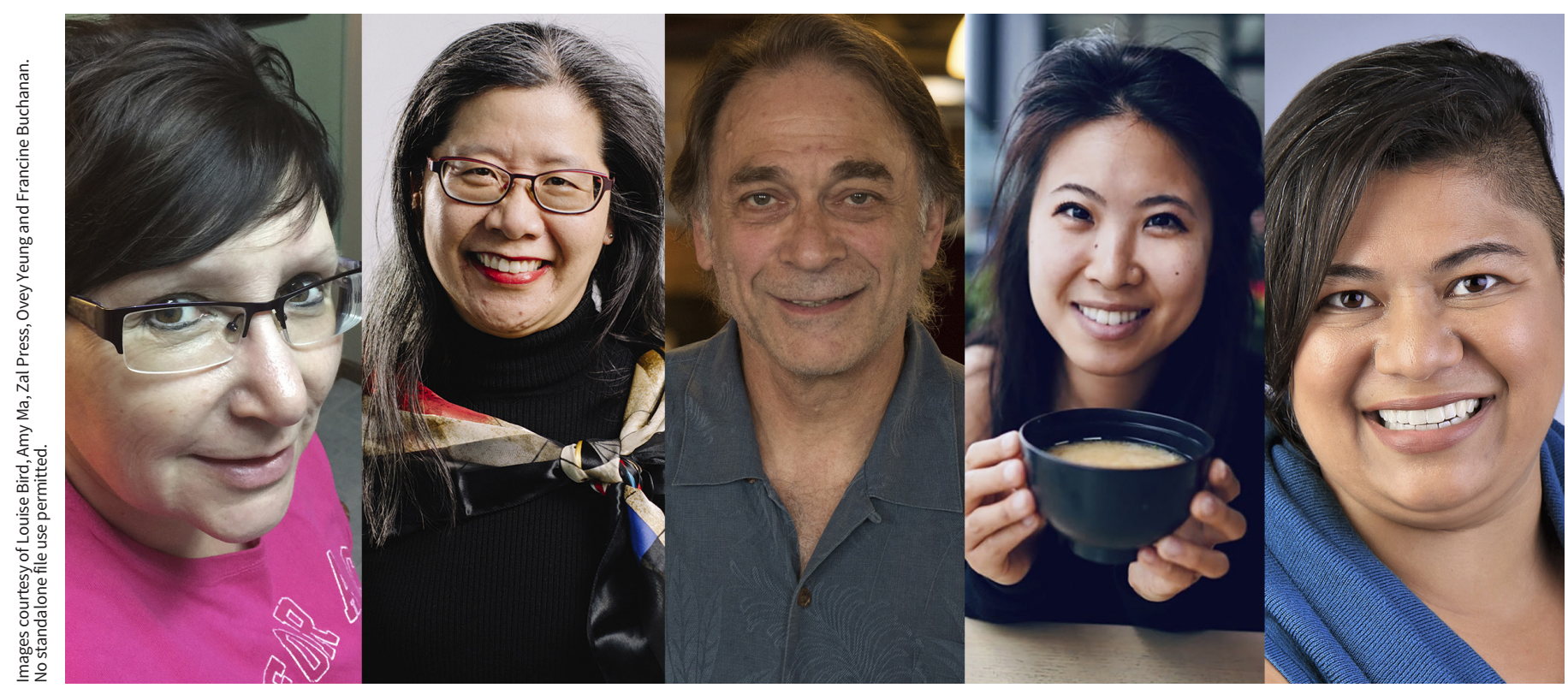

Patient partners (left to right) Louise Bird, Amy Ma, Zal Press, Ovey Yeung and Francine Buchanan share their take on meaningful engagement. 
Buchanan: The main thing I wish [they understood], and I think they do understand, is different perspectives. So if you're asking a question about the kinds of medications my child uses, that question to me is huge, because it's not just the medications the doctor prescribes. But do I answer [about] the supplements I give them? [Researchers can be] very focused on the answers they deem will help their research and not the actual way I would read that question.

\section{CMAJ: What does meaningful engagement look like in your experience?}

Bird: Engagement is when you can sit down at the table and you're comfortable enough to speak. You don't feel inferior to the other people sitting at the table... Sometimes there are only one or two patients and 10 experts, so until you feel comfortable... you might not speak up.

Ma: When you admit and acknowledge that we have to design for human differences and we centre the most marginalized first, that's the only way that we can make sure that we don't leave anyone behind.

Buchanan: Meaningful engagement is having a patient advisor embedded on a study team... like any other staff. Having the conversations that you would have with other research colleagues - you know, "Check out this data. This kind of looks weird. What do you think about it?" The challenge is we value work and productivity so highly that patients, caregivers and people with lived experiences of pain may not fit into that work structure.

Press: If patients were enabled in a way to actually hold the researchers and the research projects more accountable to being patient-oriented, that could be a really interesting reversal of the power dynamic.

Yeung: Close the [feedback] loop and keep us informed... so at least we know the impact that we're making, because that's what keeps us going.
CMAJ: What are the biggest challenges to meaningful patient and public engagement?

Buchanan: Our way of doing research is not conducive right now [to upholding] the values that we know should be practised when doing good patient engagement. In research, you write a grant, submit the grant, get the money, and then you start your research. Well, if you get the money after you've written the grant, how are you engaging patients and families in writing that grant?

Press: Culture. If a health organization, a hospital, is not part of the $80 \%$ that now have a patient and family advisory council, what's standing in the way? Is it organizational leadership that doesn't see it as a strategic priority? I would argue that it starts at the top. Patient engagement really isn't something that bubbles up from the bottom.

Bird: A lot of researchers aren't exactly sure what role patients should have. At first, for a lot of health systems, having a patient at the table was checking a box. They're coming around to realize that patients have valuable input... [but] you really have to have clear focus on what you expect your partners to provide. At lot of times you can sit at the tables for three or four meetings before the ideas really gel.

Ma: Investing properly in the time and the effort that it takes to build meaningful connections, especially with marginalized and hard to reach groups [and] especially with Indigenous people. There's no amount of parachuting just one person into a committee that is going to significantly change the structures of healthcare that continue to do harm.

Yeung: Meeting people halfway. Let's say you want to meet for coffee with somebody on LinkedIn that you don't know, but you're asking them for knowledge about a job or something. Usually, if you want something from another person, you cater to their schedule, right? [Research teams] usually schedule everything during the day and they're pretty inflexible about that.
CMAJ: Patients on social media have discussed how conversations about compensation are often awkward or one-way, and it's not always clear from the outset of a project what the commitment and compensation will be. What makes this so tricky?

Buchanan: It's the intersection of a lot of different issues that people haven't studied enough. Are [patient partners] an employee? Do they need to go through HR? If they go through HR, does that mean you have to interview them and select them for their skills and capabilities? Can you fire them? If they don't produce work, but they're a caregiver, or they're sick or hospitalized, you don't want to penalize them for that.

Ma: It's awkward because of the power imbalance, right? Maybe we're afraid to speak up because we already know the health care system is beleaguered in certain ways and we don't want to add more of a burden. But it really is a cost to us to give up the time and energy to be on a project for the long haul... If we continue not to pay patients, we will only get university-educated, upper-middleclass retirees around the table. Is that what we really want? A single parent who is juggling two jobs deserves just as much to be heard.

Bird: Some people could be retired and very wealthy, but most people are just ordinary working people. I can't afford to put a $\$ 1000$ trip on my credit card and get paid for it three months later... Gift cards have no meaning because a lot of times they have an expiry date. If you are going to reimburse someone, rather than doing it by cheque, do it by direct deposit or e-transfer so we don't have to wait.

Press: There are so many things that feed into resistance to compensating patients. Power, volunteerism... the idea if we pay patients it will compromise their objectivity. But money is not a corruptor - it's what enables participation. [CADTH's patient and community advisory committee] is a role model. They compensate us for our time equally to the compensation they provide to other experts. They went 
through a massive recruitment process almost 100 applications for a 12-member panel. Because money was on the table, the organization committed.

Yeung: There needs to be a line item on your budget... If they truly valued our information, then they'd be paying for it, because they pay for everything else.

\section{CMAJ: Where do you think you've} had the most positive impact as a patient partner? What excites you about this field, looking forward?

Buchanan: It's the little conversations that come up all the time when you're working collaboratively with colleagues that change their perspective. Those to me are the most powerful contributions I can have as a patient partner. We hear the platitudes - "Thank you so much for your input" - but that's different from the authentic, "Oh man, I never thought of that."

Bird: If you're working with another patient partner - a lot of times, there's only two of us - and really bounce off each other and get buy-in from the other other side of the table, that's the best experience because you can go a long way... It's all about teamwork. Once you feel like you're part of that team, you're golden.

Yeung: I'm really excited for health care to finally digitize. I cannot believe it took a pandemic for it to happen... I had so much trouble just like moving one file to another office. Like they fax it over, they can't even email it over, because of privacy issues or something, right? And it would take two or three weeks, and then I have to follow up. It wasn't a priority. And just not a great experience.

Ma: Every three years or so, here in the city of Montreal, we hold a simulation of a "code orange" mass casualty event. For the Montreal Children's Hospital, I recruited four adults with physical disabilities, to [play the role of] parents of children who had been injured in the code orange. It's something that I believe should be on the radar of every single emergency department, if they do these drills. There's absolutely zero guarantee that, in an emergency situation, you will only ever get able-bodied people.

Press: The most important for me is enabling people to tell their stories. Still, 10 years later, I marvel at the impact of a person opening up to health care professionals and sharing their story. Stories are traditionally, historically, culturally where we find meaning. Somebody else said this, but we live our lives not by how many breaths we take, but by how many times our breath is taken away.... Powerful moments, that's what changes the world.

\section{Diana Duong, CMAJ}

Content licence: This is an Open Access article distributed in accordance with the terms of the Creative Commons Attribution (CC BY-NC-ND 4.0) licence, which permits use, distribution and reproduction in any medium, provided that the original publication is properly cited, the use is noncommercial (i.e., research or educational use), and no modifications or adaptations are made. See: https://creativecommons.org/ licenses/by-nc-nd/4.0/ 